\title{
Antibiotic Resistance and Transfer of Extended Spectrum Beta Lactamase (ESBL) Resistant Plasmids in Pseudomonas aeruginosa Isolates from Hospitalized Patients
}

\author{
O. S. Egbule \\ Department of Microbiology, Delta State University, Abraka. \\ [Corresponding Author: E-mail: oliviaegbule@gmail.com]
}

\section{ABSTRACT}

The study was undertaken to determine antibiotic resistance, ESBL production and transfer of resistant plasmids of Pseudomonas aeruginosa. Clinical samples of urine, wound and blood were screened for Pseudomonas aeruginosa following standard microbiological procedures. Isolates of Pseudomonas aeruginosa were identified in a total of $110(18.3 \%)$ samples with higher prevalence observed in wound (43.6\%) and blood (40.0\%) samples. Identified isolates were profiled for antimicrobial susceptibility to a total of 10 antibiotics. Plasmid DNA extraction was carried out by the alkaline lysis method. Double disc synergy test (phenotypic) and PCR (genotypic) techniques were used to determine ESBL production from selected organisms while transfer of resistant genes was assessed by conjugation using broth mating procedures. Results showed high rates of resistance among organisms tested using antipseudomonal drugs. Seventy-seven $(70.0 \%)$ of the isolates were multi drug resistant (MDR), out of which $26(33.8 \%)$ and 4 (15.4\%) produced ESBL by phenotypic and genotypic methods, respectively. Plasmid profile analysis revealed that all the 77 MDR isolates harboured plasmids of $>1.5 \mathrm{~kb}$. Four ESBL producing isolates selected could transfer their resistance plasmid to a recipient $E$. coli strain $\mathrm{K}$ 12. The therapeutic challenge observed calls for an effective antimicrobial stewardship program.

Keywords: Multidrug-Resistance (MDR), ESBL production, Pseudomonas aeruginosa, antipseudomonal drugs

\section{INTRODUCTION}

Multidrug resistance is emerging globally and is of great concern especially in infections caused by Pseudomonas aeruginosa. $P$. aeruginosa is an opportunistic pathogen that thrives best in moist settings including health care settings (Lister et al., 2009). P. aeruginosa rarely colonizes healthy individuals but frequently found to spread among hospitalized patients $(>50 \%$ colonization rate) and has been implicated in most hospital acquired infections (Arora et al., 2011). The organism has innate resistance to many antibiotics including $\beta$ lactams, anti-pseudomonal Ceftazidime, aminoglycosides and ciprofloxacin (Dundar and Otkun, 2010; Potron et al., 2015), making infections they cause difficult and expensive to treat. Similarly, increasing resistance to $\beta$ lactams such as third and fourth- generation cephalosporins has become a serious global clinical problem due to the production of betalactamases. Pseudomonas aeruginosa is known to produce extended spectrum beta- lactamases (ESBLs) (Memish et al., 2012) and now frequently isolated (Potron et al., 2015.)

ESBLs are plasmid mediated enzymes, capable of hydrolyzing and inactivating a wide variety of beta-lactam antibiotics including oxyimino- $\beta$ lactams (third- and fourth- generation of cephalosporins) and aztreonam, and are inhibited by $\beta$-lactamase inhibitors, such as clavulanic acid (Paterson and Bonomo, 2005). These features are employed in the phenotypic tests used for the detection of ESBL-producing strains. The ESBL-type enzymes are categorized into two Ambler classes, A and D. The plasmid mediated antibiotic resistance facilitates the ease of spread between species. Being plasmid mediated, ESBLs are often coresistant to aminoglycosides, sulfonamides and quinolones. Therefore, infections caused by such strains may be difficult to treat due to limited therapeutic option

The increasing resistance to beta-lactam antibiotics has led to an increased focus by 
researchers to determine the mechanisms of resistance. Until recently only a few studies have been carried out to detect such mechanism in Nigeria. The present study was conducted with an aim to detect the prevalence of ESBL-producing Pseudomonas aeruginosa isolates, their susceptibility to selected antibiotics and transfer of resistance from clinical samples of two government funded hospitals in Delta State, Nigeria.

\section{MATERIALS AND METHODS \\ Study Site and Collection of Samples}

The study examined 600 samples collected from wound, urine and blood of hospitalized patients in 2 general hospitals at Warri and Agbor located in Delta State, Nigeria. One hundred of each sample type was collected based on the principle of one sample type from one patient. The samples were collected in 2014 after obtaining approval from the post graduate thesis research committee Delta State University and the hospitals ethical committee. Written or verbal consent from the patients or their guardians was obtained before samples were collected from the patients. The samples were collected aseptically using sterile swab stick and universal bottles following standard microbiological guidelines (Collee and Marr, 2008).

\section{Culture and Identification of Pseudomonas aeruginosa}

Following aseptic collection, urine and wound swabs were cultured on Blood and MacConkey agar media. For blood culture, samples were first inoculated into tryptic soya broth to enhance growth and incubated aerobically at 37 ${ }^{\circ} \mathrm{C}$ for $24 \mathrm{hrs}$. The broths were then sub cultured on 5\% sheep blood agar and MacConkey agar. Cultures showing signs of growth were followed-up by examining the broth daily and conducting a final sub-culture at the end of the $7^{\text {th }}$ day or at the appearance of turbid culture. The plates were incubated aerobically overnight at $37^{\circ} \mathrm{C}$ and observed for bacteria growth. $P$. aeruginosa were identified by their colony characteristics, pigment production, staining characters, motility and other relevant biochemical tests following standard methods of identification (Palleroni, 1984).

\section{Antimicrobial Susceptibility Testing}

The antibiotic susceptibility of $P$. aeruginosa to selected antibiotics was determined using Mueller-Hinton agar (MHA) plates (Hi media, India) and by the disc diffusion method according to the CLSI guidelines (CLSI, 2012). Multi-antimicrobial discs containing the following antibiotics and their concentration were used; amoxicillin-clavulanic acid (A-30 $\mu \mathrm{g})$, ceftazidime (CZ-30 $\mu \mathrm{g})$, cefotaxime (CF$30 \mu \mathrm{g}$ ), cefuroxime (CR-30 $\mu \mathrm{g})$, cefixime (CX-5 $\mu \mathrm{g})$, gentamicin (G-10 $\mu \mathrm{g})$, ciprofloxacin (C-5 $\mu \mathrm{g})$, ofloxacin (O-5 $\mu \mathrm{g})$, trimethoprimsulfamethoxazole (S-25 $\mu \mathrm{g})$, and nitrofurantoin $(\mathrm{N}-300 \mu \mathrm{g})$. Zones of inhibition around each disc were measured and recorded as sensitive or resistant. Multi drug resistance (MDR) among the isolates defined as resistance in $\geq 3$ antibiotics were selected.

\section{Phenotypic Detection of ESBL Production}

Detection of ESBL production by MDR Pseudomonas aeruginosa strains was performed on MHA plates by Double disc synergy test (DDST) as described by Jarlier et al. (1988). Mueller Hinton agar (Hi Media, India) was inoculated with $0.5 \mathrm{McF}$ arland standard inoculum of the MDR Pseudomonas aeruginosa isolate using sterile cotton swab. An amoxicillinclavulanic acid disc was placed in the centre of the plate and the test antibiotics (ceftazidime and cefotaxime) were placed at $20 \mathrm{~mm}$ distance (center to center) from the amoxicillin-clavulanic acid disc. The plates were incubated at $37^{\circ} \mathrm{C}$ for 24hrs. Enhancement of zone of inhibition towards amoxicillin -clavulanic acid was interpreted as ESBL producer.

\section{Plasmid DNA Isolation and Agarose Gel Electrophoresis}

Plasmid DNA extraction was carried out by the alkaline lysis method of Birnboin and Dolly (1979). The extracted DNA were resolved on $1.5 \%$ agarose gel. Electrophoresis was conducted on a horizontal gel apparatus for 45 mins at $90 \mathrm{~V}$ using $0.5 \%$ Tris - Borate - EDTA (TBE) buffer ( $\mathrm{pH} .8 .3)$. The molecular size of the 
plasmids was estimated by comparing with standard plasmids of known molecular weight in the gel.

\section{Molecular Detection of ESBL Genes}

The ESBL phenotypic positive isolates were genotyped by performing PCR using specific primers for the detection of bla CTX-M, bla TEM, and bla SHV genes as shown in Table 1. Here 5 $\mu \mathrm{l}$ DNA was used in $25 \mu \mathrm{l}$ reaction mixture containing 2.5U of Taq polymerase (Thermo Scientific, Germany), $200 \mu \mathrm{m}$ each of dATP, dGTP, dTTP and dCTP, $0.2 \mu \mathrm{m}$ each primer, $1.5 \mathrm{mM} \mathrm{MgCl}$. PCR amplification conditions were initial denaturation at $94^{\circ} \mathrm{C}$ for 10 minutes followed by 35 cycles of denaturation for $30 \mathrm{~s}$ at $94^{\circ} \mathrm{C}, 1$ minute of annealing at $56^{\circ} \mathrm{C}$, extension at $72^{\circ} \mathrm{C}$ for 1 minute and the final extension was done at $72^{\circ} \mathrm{C}$ for 10 minutes. The PCR amplification products were resolved in $1.5 \%$ agarose gel. Staining of the gel was done with ethidium bromide in a TEA buffer. At $100 \mathrm{~V}$ for $60 \mathrm{~min}$ and visualized under UV transilluminator (Alliance 4.7).

\section{Transfer of Antibiotic Resistance}

Transfer of resistance by conjugation using broth mating procedure as described by Ahmad et al. (1994) was performed. All MDR $P$. aeruginosa with ESBL-positive genotype and plasmid free $E$. coli K-12 showing sensitivity to all tested antibiotics in this study were used as donor and recipient cells, respectively

Table 1: Primer sequence for detection of ESBL genes in $P$. aeruginosa clinical isolates

\begin{tabular}{llll}
\hline GENES & PRIMER SEQUENCE $(5 \rightarrow 3)$ & $\begin{array}{l}\text { AMPLICON } \\
\text { SIZE (BP) }\end{array}$ & REFERENCE \\
\hline CTX-M 2-F & ATGATGACTCAGAGCATTCG & 865 & - \\
CTX-M 2- R & TGGGTTACGATTTTCGCCGC & - & Nedjai et al., 2013 \\
SHV- $\mathbf{F}$ & TCAGCGAAAACACCTTG & 471 & - \\
SHV-R & TCCCGCAGATAAATCACC & - & Lal et al.,2007 \\
TEM-F & CTTCCTGTTTTTGCTCACCCA & 717 & - \\
TEM-R & TACGATACGGGAGGGCTTAC & - & Lal et al., 2007 \\
\hline
\end{tabular}

Overnight cultures of donor and recipient cells were mixed at a ratio of $1: 2$ in $7 \mathrm{ml}$ of Luria Bertani (LB) broth and incubated for 4 hours at $37 \quad{ }^{\circ} \mathrm{C}$. Afterwards, lactose fermenting transconjugants were selected on MacConkey agar plates containing amoxicillin clavulanic acid and cefotaxime or ceftazidine $(300 \mu \mathrm{g} / \mathrm{ml})$. Susceptibility tests and genotypic detection of ESBL genes by PCR were performed on the lactose fermenting transconjugants to confirm transfer as previously described. For controls, the donors and recipient were each grown separately in LB broth for 4 hours at $37^{\circ} \mathrm{C}$ and the colony forming units of the recipient was counted.

\section{Statistical/Data analysis}

Differences in the prevalence of $P$. aeruginosa in the 2 locations sampled was determined using student unpaired T-test with $p$ value of $<0.05$ considered statistically significant.

\section{RESULTS}

Pseudomonas aeruginosa were isolated from 110 clinical samples from a total of 600 samples collected. The highest number were isolated from wound $48(43.6 \%)$ followed by blood $44(40.0 \%)$, then urine (18\%) (Table 2), $p$ $=0.743$, T-test). Antimicrobial susceptibility tests reveal Pseudomonas aeruginosa had a high prevalence of resistance to amoxicillin clavulanic acid, ceftazidime (an antipseudomonal drug) with cases of $100 \%$ resistance recorded in wound and blood samples. Resistance was also observed in Pseudomonas aeruginosa isolates tested with trimethoprim-sulfamethoxazole. The pattern of resistance observed in ciprofloxacin and gentamicin (antipseudomonal drugs) varied from one location and sample type to another and was equally high. Resistance of $70.6 \%$ and $45.5 \%$ were observed against gentamicin and ciprofloxacin, respectively in Pseudomonas aeruginosa isolated from wound and blood 
samples. Some degree of $P$. aeruginosa susceptibility was however, observed when treated with nitrofurantoin (Table 3).

Results also showed that $77(70.0 \%)$ of the Pseudomonas aeruginosa isolated were observed to be MDR strains. The frequency of occurrence of MDR strains was higher in wound $(43.6 \%)$ and blood (40.0\%) samples. Additionally, plasmid profile analysis revealed that all the 77 MDR isolates harboured plasmids of $>1.5 \mathrm{kp}$ (Figure 1). The presence of multiple plasmids was observed. It is notable that similar plasmids sizes were observed in all MDR isolate harboring plasmids originating from wound and blood of GHA. Of 77 Pseudomonas aeruginosa isolates, $26(33.8 \%)$ phenotypically ESBL- positive isolates were identified (Table 4). Among the 26 ESBLpositive isolates in phenotypic tests, the presence of $4(15.4 \%)$ blaTEM genes encoding ESBL was detected (Table 5). No bla SHV and bla CTX-M gene was detected.

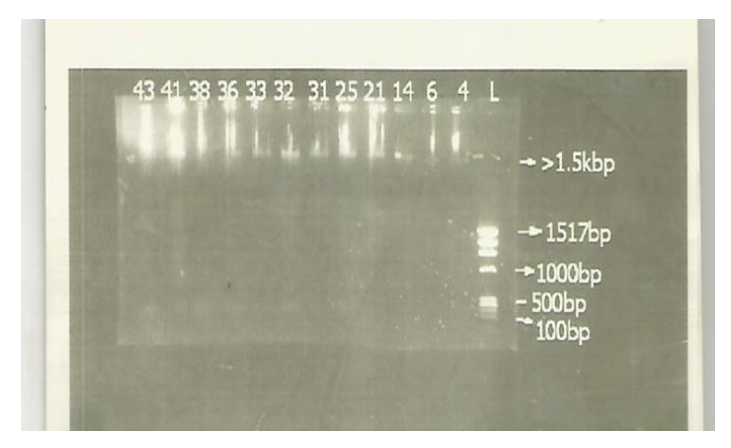

Figure1: plasmid profile of some pseudomonas aeruginosa isolates.

Lane L molecular laders, lanes $43,41.38,36$, $33,32,31,25,21,14,6,4$ are pseudomonas aeruginosa isolates bearing plasmids of $>1.5 \mathrm{kp}$

To investigate the transferability of the plasmids, the 4 MDR Pseudomonas aeruginosa ESBL-positive genotypes were selected and conjugated with E. coli K-12. All Pseudomonas aeruginosa selected transferred their ESBL gene and resistant plasmids to $E$. coli $\mathrm{K}-12$ recipient (Table 5).

Table 2: Distribution of clinical isolates of Pseudomonas aeruginosa obtained from Warri and Agbor General Hospitals, Delta State

\begin{tabular}{lllll}
\hline \multirow{5}{*}{ SAMPLE } & WARRI & AGBOR & TOTAL & \\
TYPE & $\mathbf{n}(\%)$ & $\mathbf{n}(\%)$ & $(\%)$ & p-VALUE \\
\hline Urine & $14(28.0)$ & $4(3.6)$ & $18(16.4)$ & 0.742428 \\
Wound & $14(28.0)$ & $34(56.7)$ & $48(43.6)$ & \\
Blood & $22(44.0)$ & $22(36.7)$ & $44(40.0)$ & \\
Total & $50(45.5)$ & $60(54.5)$ & $110(18.3)$ & \\
\hline
\end{tabular}

\section{DISCUSSION}

In recent times, emergence of multidrug resistance (MDR) has jeopardized the use of many antibiotics and this is of huge concern. Pseudomonas aeruginosa with particular propensity for antibiotic resistance has been implicated in high mortality rates in many studies (Hirsch and Tam, 2010; Lambert et al., 2011). Equally reported is acquired resistance by the production of plasmid mediated ESBL enzymes (Manchanda and Singh, 2003). In this study, most of the isolates of Pseudomonas aeruginosa were obtained from wound and Blood (Table 2). Higher prevalence of MDR was also obtained from wound and blood. Various articles have associated Pseudomonas aeruginosa with increased mortality in blood stream infection (Peña et al., 2012; Pachori et al., 2019; Recio et al., 2020) and wound infection (Nasirmoghadas et al., 2018). 
Egbule: Antibiotic Resistance and Transfer of Extended Spectrum Beta...

Table 3: Susceptibility pattern of clinical isolates of $P$. aeruginosa obtained from Warri and Agbor General Hospitals, Delta State

\begin{tabular}{|c|c|c|c|c|c|c|c|c|c|c|c|}
\hline \multirow[t]{2}{*}{ LOCATION } & \multirow[t]{2}{*}{ SAMPLE } & \multicolumn{10}{|c|}{ ANTIMICROBIAL AGENTS } \\
\hline & & A & $C X$ & $\mathrm{CZ}$ & CR & CF & G & 0 & C & $\mathbf{N}$ & S \\
\hline \multirow[t]{3}{*}{$\overline{\text { GHW }}$} & Urine & $14(100.0)$ & $6(42.9)$ & $8(57.1)$ & $8(57.1)$ & $6(42.9)$ & 6(42.9) & $3(21.4)$ & $3(21.4)$ & $1(7.1)$ & $8(57.1)$ \\
\hline & Blood & $12(54.6)$ & $19(86.4)$ & $19(86.4)$ & $19(86.4)$ & $12(54.6)$ & $4(18.2)$ & $4(18.2$ & $2(9.1)$ & $1(4.6)$ & $12(54.6)$ \\
\hline & Wound & $14(100.0)$ & $12(85.7)$ & $14(100.0)$ & $6(42.9)$ & $8(57.1)$ & $8(57.1)$ & $2(14.3)$ & $4(28.6)$ & $4(28.6)$ & $8(57.1)$ \\
\hline \multirow[t]{3}{*}{ GHA } & Urine & $4(100.0)$ & $3(75.0)$ & $3(75.0)$ & $3(75.0)$ & $2(50.0)$ & $2(50.0)$ & $0(0.0)$ & $1(25.0)$ & $0(0.0)$ & $2(50.0)$ \\
\hline & Blood & $20(90.9)$ & $20(90.9)$ & $20(90.9)$ & $20(90.9)$ & $17(77.3)$ & $12(54.6)$ & $7(31.8)$ & $10(45.5)$ & $7(31.8)$ & $9(40.9)$ \\
\hline & Wound & $29(85.3)$ & $27(79.4)$ & $34(100.0)$ & $24(70.6)$ & $12(35.3)$ & $24(70.6)$ & $10(29.4)$ & $7(20.6)$ & $8(23.5)$ & $13(38.2)$ \\
\hline
\end{tabular}

$\mathrm{A}=$ amoxicillin-clavulanic acid; CX = cefixime; $\mathrm{CZ}$ = ceftazidime; $\mathrm{CR}=$ cefuroxime; $\mathrm{CF}=$ cefotaxime; $\mathrm{G}$ = gentamicin; $\mathrm{O}=$ ofloxacin; $\mathrm{C}=$ ciprofloxacin; $\mathrm{S}=$ trimethoprim-sulfamethoxazole; $\mathrm{N}=$ nitrofurantoin $\mathrm{GHW}=$ General hospital Warri; $\mathrm{GHA}=$ General hospital Agbor 
Nigerian Journal of Basic and Applied Science (June, 2021), 29(1): 90-99

Table 4: Prevalence of MDR and ESBL phenotype of Pseudomonas aeruginosa

\begin{tabular}{llll}
\hline $\begin{array}{l}\text { HOSPITAL } \\
\text { LOCATION }\end{array}$ & SAMPLE TYPE & $\begin{array}{l}\text { PREVALENCE OF MDR } \\
\text { SAMPLES } \\
\mathbf{n}(\%)\end{array}$ & ESBL PHENOTYPE \\
\hline Warri & Urine & $9(11.7)$ & \\
& Wound & $12(15.6)$ & $1(3.8)$ \\
& Blood & $10(12.9)$ & $10(38.5)$ \\
Agbor & Urine & $2(2.6)$ & $3(11.5)$ \\
& Wound & $25(32.5)$ & $0(0.0)$ \\
& Blood & $19(24.7)$ & $8(30.8)$ \\
Total & & $77(70.0)$ & $4(15.4)$ \\
\hline
\end{tabular}

Table 5: Transfer of ESBL genotype in some selected Pseudomonas aeruginosa donor strains

\begin{tabular}{lll}
\hline DONOR STRAIN & RESISTANCE PATTERN & ESBL GENOTYPE \\
\hline P.a 01 & A CX CZ CF CR N G C O S & blaTEM \\
P.a 02 & A CX CZ CF CR G C O S & blaTEM \\
P.a 03 & A CX CZ CF CR G C O S & blaTEM \\
P.a 04 & A CX CZ CF CR G C O S & blaTEM \\
\hline
\end{tabular}

$P$. a; Pseudomonas aeruginosa

The prevalence of multi-drug resistance Pseudomonas aeruginosa has increased over the last few decades and varies from one geographical area to another. Multidrug resistantt Pseudomonas aeruginosa prevalence of 15 to $30 \%$ has been reported in most developed regions (Walkty et al., 2017; Sader et al., 2018) while lower prevalence was reported in Morocco $(0 \%)$, Saudi Arabia (7.3\%) and Qatar (8.1\%) and high-level resistance was reported in Bahrain (86\%), Egypt (75.6\%), Lebanon $(64.5 \%)$, Jordan $(52.5 \%)$ and Palestine (47.6\%) (Al-Orphaly, 2021). The low prevalence reported for instance in Saudi Arabia and Qatar was attributed to their well-structured health care systems as well as antibiotic-prescribing culture.

In contrast, this study reported $70.0 \%$ MDR Pseudomonas aeruginosa, this reflects the high usage of antibiotics coupled with the low rate of sensitivity testing to inform choice of antibiotic therapy. Antimicrobial stewardship programs are limited in lowand middle-income countries (Nathwani et al., 2019) and therefore, effective antimicrobial stewardship programs are crucial to the fight against spread of MDR, including $P$. aeruginosa (Tacconelli, 2018). The choice of antibiotics in our government owned hospitals is essentially based on treatment guidelines.

Resistance to antipseudomonal drugs such as ceftazidime actually reached an alarming level in this study. High prevalence of ceftazidime resistance in this study, ranged between 100 and $90.9 \%$ among wound and blood Pseudomonas aeruginosa isolates, respectively (Table 3 ). A similar study by Hussain et al. (2017) in Pakistan, ceftazidime resistance was $100 \%$. Pakistan like Nigeria indulge in high frequency of drug use, antibiotics are easily available making resistance to antibiotics increasing rapidly (Solé et al., 2015). High resistance to other $3^{\text {rd }}$ generation cephalosporins was observed in this study and is attributable to ESBL production. Pseudomonas aeruginosa isolates were also resistant to the other two antipseudomonal agents (ciprofloxacin and gentamicin) determined in this study. 
Egbule: Antibiotic Resistance and Transfer of Extended Spectrum Beta...

These drugs are used routinely as therapeutic and prophylactic treatment.

Twenty-six (33.8\%) (Table 4) MDR produced ESBL by phenotypic method in this study. Comparable percentage prevalence of 37.2 was reported by Rani et al. (2016). Slightly higher and lower figures of $42.3 \%$ and $22.2 \%$ have been reported (Goel et al., 2013; Senthamarai et al., 2013). Genotypic detection of Pseudomonas aeruginosa isolates encoding ESBL genes from TEM family was observed in $15.4 \%$ in this study. The low prevalence may be because the ESBL enzymes found in Pseudomonas aeruginosa strains are primarily $\beta$ lactamases from the OXA, PER, GES (Potron et al., 2015; Garza-Ramos et al., 2015), VEB (Vatcheva-Dobrevska et al., 2013; Potron et al., 2015), BEL (Poirel et al., 2005; Glupczynski et al.,2010; Potron et al., 2015), and PME (Tian et al., 2011) ESBL family.

To ascertain the possible role of plasmid in the dissemination of beta lactamases resistance genes, the 4 genotypic ESBL positive Pseudomonas aeruginosa isolates were conjugated with $E$. coli $\mathrm{K}-12$ recipient cell. The donor cells transferred their resistance genes to the recipient via conjugation and this is of grave implication as it exacerbates the spread of antibiotic resistance in the community thus threatening human health and increasing disease burden in the community. Of note is resistance to ceftazidime, ciprofloxacin and gentamicin observed in all the ESBL positive genes. This is due to the coexistence of genes encoding drug resistance to other antibiotics on the plasmids which encode ESBL (Nathisuwan et al., 2001).

\section{CONCLUSION}

MDR Pseudomonas aeruginosa isolates were most common in blood and wound samples and were found to be resistant to the antipseudomonal drugs tested particularly ceftazidime. Although low prevalence of genotypic ESBL genes was observed, a high rate of transfer of plasmids harboring these genes was detected in this study.

\section{ACKNOWLEDGEMENTS}

I acknowledge the contributions of Late Dr. O. E Nwafor and Mr Bright Igere of Lahor lab, Benin City for helping out with the molecular analysis.

\section{REFERENCES}

Ahmad, I., Yadava, J.N.S. \& Ahmad, S. (1994). High level transferable resistance among $\mathrm{E}$. coli. Indian Journal of Animal Science, 64: 439-445.

Al-Orphaly, M., Hadi, H. M., Eltayeb, F. K., Al-Hail, H., Samuel, B. G. \& Ali A. (2021). Epidemiology of MultidrugResistant Pseudomonas

aeruginosa in the Middle East and North Africa Region. Antimicrobial Agents and Chemotherapy, 6(3): e00202-21

Arora, D., Jindal, N., Kumar, R. and Romit, M. (2011). Emerging Antibiotic Resistance in Pseudomonas: A Challenge. International Journal of Pharmacy and Pharmaceutical Sciences, 3: 1488-1491.

Birnboim, H.C. \& Doly, J.A. (1979). Rapid alkaline extraction procedure for screening recombinant plasmid DNA. Nucleic Acids Research, 7(6): 1513-1523.

Clinical and Laboratory Standards Institute (CLSI). (2012). Performance Standards for Antimicrobial Susceptibility Testing; Twenty second Informational Supplement. CLSI Document M100-S22. Clinical and Laboratory Standards Institute, Wayne, 32(1).

Collee, J.G. \& Marr, W. (2008). Specimen collection, culture containers and media, In: Mackie and McCartney Practical Medical Microbiology. 
G.J. Collee, G.A. Fraser, B.P. Marmon, and A. Simmons, (Eds.) Elsevier, Canada, Pp. 432

Dundar, D. \& Otkun, M. (2010). InVitro efficacy of synergistic antibiotic combinations in multidrug resistant pseudomonas aeruginosa strains. Yonsei Medical Journal, 51: 111116

Garza-Ramos, U., Barrios, H., ReynaFlores, F., Tamayo-Legorreta, E., Catalan-Najera, J.C., Morfin-Otero, R., Eduardo, R., Volkow, P., Patricia, C., Gonzalez, A., Jesus, G., Marisela, D.R.G., Maria, V. \& Jesus, S. (2015). Widespread of ESBL- and carbapenemase GEStype genes on carbapenemresistant Pseudomonas aeruginosa clinical isolates: a multicenter study in Mexican hospitals. Diagnostic Microbiology and Infectious Disease. 8: 135137.

Glupczynski, Y., Bogaerts, P., Deplano, A., Berhin, C., Huang, T.D., Van Eldere, J. \& Rodriguez-Villalobos, H. (2010). Detection and characterization of class $A$ extended-spectrum- $\beta$-lactamaseproducing Pseudomonas aeruginosa isolates in Belgian hospitals. Journal of Antimicrobial Chemotherapy. 65(5): 866-871.

Goel, V., Hogade, S. \& Karadesai, S. (2013). Prevalence of extendedspectrum beta-lactamases, AmpC beta-lactamase, and mettalo-betalactamase producing Pseudomonas aeruginosa and Acinetobacter baumannii in an intensive care unit in a tertiary care hospital. Journal of the Scientific Society, 40(1): 28.

Hirsch, E.B. \& Tam, V.H. (2010). Impact of multi drug resistant Pseudomonas aeruginosa infection on patient outcomes. Expert review of Pharmaco Economics and
Outcomes Research, 10(4): 441451.

Hussain, A., Shaik, S., Ranjan, A., Nandanwar, N., Tiwari, S.K., Majid, M., Baddam, R., Qureshi, I.A., Semmler, T., Wieler, L.H., Islam, M.A., Chakravortty, D. \& Ahmed, N. (2017). Frontiers in Microbiology, 8: 2120.

Jarlier, V., Nicolas, M.H., Fournier, G. \& Philippon, A. (1988). Extended spectrum $\beta$-lactamases conferring transferable resistance to newer $\beta$ lactam agents in Enterobacteriaceae: Hospital prevalence and susceptibility patterns. Reviews of Infectious Diseases, 10: 867-878.

Lal, P., Kapil, A., Das, BK. \& Sood, S. (2007). Occurrence of TEM \& SHV gene in extended spectrum $\beta$ lactamases (ESBLs) producing Klebsiella sp. isolated from a tertiary care hospital. Indian Journal of Medical Research, 125: 173-178.

Lambert, M.L., Suetens, C., Savey, A., Palomar, M., Hiesmayr, M., Morales, I., Agodi, A., Frank, U., Mertens, K., Schumacher, M. \& Wolkewitz, M. (2011). Clinical outcomes of health-careassociated infections and antimicrobial resistance in patients admitted to European intensivecare units: a cohort study. Lancet Infectious Diseases, 11: 30-38.

Lister, P.D., Wolter, D.J. \& Hanson, N.D. (2009). Antibacterial-resistant Pseudomonas aeruginosa: clinical impact and complex regulation of chromosomally encoded resistance mechanisms. Clinical Microbiology Reviews, 22: 582610.

Manchanda, V. \& Singh, N.P. (2003). Occurrence and detection of AmpC beta-lactamases among Gram-negative clinical isolates using a modified three-dimensional 
Egbule: Antibiotic Resistance and Transfer of Extended Spectrum Beta...

test at Guru Tegh Bahadur Hospital, Delhi, India. Journal of Antimicrobial Chemotherapy, 51: 415-418.

Memish, Z.A., Shibl, A.M., Kambal, A.M., Ohaly, Y.A., Ishaq, A. \& Livermore, D.M. (2012). Antimicrobial resistance among non-fermenting gram-negative bacteria in Saudi Arabia. Journal of Antimicrobial Chemotherapy, 67(7): 1701-1705.

Nasirmoghadas, P., Yadegari, S., Moghim, S., Esfahani, B.N., Fazeli, $H_{\text {., }}$ Poursina, F., Hosseininassab, S.A. \& Safaei, H.G. (2018). Evaluation of biofilm formation and frequency of multidrug-resistant and extended drug-resistant strain in Pseudomonas aeruginosa isolated from burn patients in Isfahan. Advanced Biomed Research, 7: 61.

Nathisuwan, S., Burgess, D.S. \& Lewis, J.S. (2001). Extended-spectrum beta-lactamases: Epidemiology, detection, and treatment. Pharmacotherapy, 21: 920-928.

Nathwani, D., Varghese, D., Stephens, J., Ansari, W., Martin, S. \& Charbonneau, C. (2019). Value of hospital antimicrobial stewardship programs [ASPs]: a systematic review. Antimicrobial Resistance and Infection Control, 8(1): 1-13.

Nedjai, S., Barguigua, A., Djahmi, N., Jamali, L., Zerouali, K., Dekhil, M. \& Timinouni, M. (2013). Prevalence and characterization of extended spectrum betalactamase- producing Enterobacter cloacae strains in Algeria. Journal of Infection in Developing Countries, 7(11): 804-811.

Pachori, P., Gothalwal, R. \& Gandhi, P. (2019). Emergence of antibiotic resistance Pseudomonas aeruginosa in intensive care unit; a critical review. Genes and Diseases, 6(2): 109-119.
Palleroni, N.J. (1984). Pseudomonadaceae: Bergey's Manual of Systematic Bacteriology. Williams and Wilkins, Baltimore, Pp. 594

Paterson, D.L. \& Bonomo, R.A. (2005). Extended-spectrum $\beta$-lactamases: a clinical update. Clinical Microbiology Reviews, 18: 657686.

Peña, C., Suarez, C., Gozalo, M., Murillas, J., Almirante, B., Pomar, V., Aguilar, M., Granados, A., Calbo, E., Rodríguez-Baño, J, Rodríguez, F., Tubau, F., Martínez-Martínez, L. and Oliver, A. (2012). Prospective multicenter study of the impact of carbapenem resistance on mortality in Pseudomonas aeruginosa bloodstream infections. Antimicrobial Agents and Chemotherapy, 56: 12651272.

Poirel, L., Brinas, L., Verlinde, A., Ide, L. \& Nordmann, P. (2005). BEL-1, a novel clavulanic acid-inhibited extended-spectrum $\beta$-lactamase, and the class 1 integron $\ln 120$ in Pseudomonas aeruginosa. Antimicrobial Agents and Chemotherapy, 49: 3743-3748.

Potron, A., Poirel, L. \& Nordmann, P. (2015). Emerging broad-spectrum resistance in Pseudomonas aeruginosa and Acinetobacter baumannii: mechanisms and epidemiology. International Journal of Antimicrobial Agents, 45: 568585.

Rani, S. V., Rao, K. R., Ravinder, S. \& Kanakadurga, P. (2016) Prevalence of extended spectrum beta lactamases (ESBL) producing Pseudomonas aeruginosa isolates from burn patients," Proceedings of the International Journal of Contemporary Medical Research, 5 (3): 1297-1300.

Recio, P., Mancheno, M., Viedma, E., Villa, J., Orellana, M., Lora-Tamayo, J. \& Chaves, F. (2020). Predictors of 
Mortality in Bloodstream Infections

Caused by Pseudomonas aeruginosa: Impact of Antimicrobial Resistance and Bacterial Virulence. Antimicrobial Agents and Chemotherapy, 64(2): e01759-19.

Sader, H.S., Castanheira, M., Duncan, L.R. \& Flamm, R.K. (2018). Antimicrobial susceptibility of Enterobacteriaceae and Pseudomonas aeruginosa isolates from United States medical centers stratified by infection type: results from the International Network for Optimal Resistance Monitoring (INFORM) surveillance program. Diagnostic Microbiology and Infectious Disease, 92: 69-74.

Senthamarai, S., Sivasankari, S. \& Kumudhavathi, S. (2013). Susceptibility pattern of ESBL strains of $P$. aeruginosa in a tertiary care hospital, Kanchipuram, Tamilnadu. International Journal of Recent Scientific Research, 4: 1748-1750.

Solé, M., Fàbrega, A., Cobos-Trigueros, N., Zamorano, L., Ferrer-Navarro, M., Ballesté-Delpierre, C., Reustle, A., Castro, P., Nicolas, J.M., Oliver, A., Martinez, J.A. \& Vila, J. (2015). In vivo evolution of resistance of Pseudomonas aeruginosa strains isolated from patients admitted to an intensive care unit: mechanisms of resistance and antimicrobial exposure. Journal of Antimicrobial Chemotherapy, 70(11): 30043013.
Tacconelli, E., Sifakis, F., Harbarth, S., Schrijver, R., van Mourik, M., Voss, A., Sharland, M., Rajendran, N.B. \& Rodriguez-Bano, J. (2018). Surveillance for control of antimicrobial resistance. Lancet Infectious Diseases, 18: e99-e106.

Tian, G. B., Adams-Haduch, J.M., Bogdanovich, T., Wang, H.N. \& Doi, Y. (2011). PME-1, an extended-spectrum $\beta$-lactamase identified in Pseudomonas aeruginosa. Antimicrobial Agents and Chemotherapy, 55: 27102713.

Vatcheva-Dobrevska, R., Mulet, X., Ivanov, I., Zamorano, L., Dobreva, E., Velinov, T., Todor, K. \& Antonio, O. (2013). Molecular epidemiology and multidrug resistance mechanisms of Pseudomonas aeruginosa isolates from Bulgarian hospitals. Microbial Drug Resistance, 19(5): 355-361.

Walkty, A., Lagace-Wiens, P., Adam, H., Baxter, M., Karlowsky, J., Mulvey, M.R., McCracken, M. \& Zhanel, G.G. (2017). Antimicrobial susceptibility of 2906 Pseudomonas aeruginosa clinical isolates obtained from patients in Canadian hospitals over a period of 8 years: Results of the Canadian Ward surveillance study (CANWARD), 2008-2015. Diagnostic Microbiology and Infectious Disease, 87: 60-63. 